\title{
RHINOLOGY
}

\section{Application of a symptoms score questionnaire after conjunctivodacryocystorhinostomy: outcomes}

\section{L'applicazione di un questionario sui sintomi dopo congiuntivodacriocistorinostomia: risultati}

\author{
Andrea landelli1,2, Andrea Luigi Camillo Carobbio ${ }^{1,2}$, Renata Migliardi³, Maurizio Catalani4 ${ }^{4}$, Francesco Mazzola ${ }^{5}$, \\ Giampiero Parrinello ${ }^{1}$, Giorgio Peretti ${ }^{1,2}$, Frank Rikki Canevari ${ }^{1,2}$ \\ ${ }^{1}$ IRCCS Ospedale Policlinico San Martino, Genoa, Italy; ${ }^{2}$ Department of Surgical Sciences and Integrated Diagnostics (DISC), \\ University of Genoa, Genoa, Italy; ${ }^{3}$ Department of Ophthalmology, Ospedale Policlinico di Monza, Monza, Italy; ${ }^{4}$ Department of \\ Otorhinolaryngology, Istituto Clinico Cellini Humanitas, Turin, Italy; ${ }^{5}$ Department of Otorhinolaryngology, Head and Neck Surgery, \\ National Cancer Institute Regina Elena, Rome, Italy
}

\section{SUMMARY}

Objective. To evaluate medium/long term outcomes and patient satisfaction through relief of symptoms and improved quality of life (QoL) after Jones tube conjunctivodacryocystorhinostomy (JT-CDCR) using the Naso Lacrimal Duct Obstruction symptom-score (NLDO-SS).

Methods. We conducted a retrospective, non-comparative, multicentric study including patients with complete obstruction of the superior and inferior proximal lacrimal drainage system. All patients underwent JT-CDCR, and the patency of the tube was evaluated with saline irrigation and endoscopic examination. We assessed patient satisfaction and quality of life administering the NLDO-SS.

Results. We enrolled 16 patients, for a total of 21 eyes operated. The success rate for procedures was $81 \%$. The success rate for single parameters was globally $95.9 \%$; if considered separately, ocular symptoms and nasal symptoms were respectively $94.3 \%$ and $100 \%$.

Conclusions. JT-CDCR was a reliable procedure, able to solve symptoms in a majority of patients and guaranteed a good quality of life over a long period of time

KEY WORDS: conjunctivodacryocystorhinostomy, nasolacrimal duct obstruction, epiphora, symptom score, quality of life

\section{RIASSUNTO}

Obiettivo. Valutare gli esiti a lungo termine e la soddisfazione del paziente, attraverso la risoluzione della sintomatologia e il miglioramento della qualità della vita (QoL) dopo intervento di congiuntivodacriocistorinostomua e posizionamento di Tubo di Jones CDCR$J$ T, mediante l'utilizzo del questionario "Naso Lacrimal Duct Obstruction Symptoms-Score (NLDO-SS)".

Metodi. Abbiamo condotto uno studio retrospettivo, non comparativo, multicentrico, includendo pazienti con ostruzione completa della lacrimale prossimale superiore e inferiore. Tutti i pazienti sono stati sottoposti a JT-CDCR, la pervietà del tubo di Jones è stata valutata con irrigazione di soluzione fisiologia ed endoscopia trans-nasale. A ciascun paziente è stato poi somministrato il questionario NLDO-SS.

Risultati. Abbiamo arruolato 16 pazienti, per un totale di 21 occhi operati. Il tasso di successo delle procedure è stato dell'81\%. Il tasso di successo per i singoli parametri ̀̀ stato globalmente del 95,9\%; se considerati separatamente, i sintomi oculari e quelli nasali erano rispettivamente del 94,3\% e del $100 \%$.

Conclusioni. L'intervento di JT-CDCR ha dimostrato di essere in grado di risolvere $i$ sintomi nella maggior parte dei pazienti e di garantire una buona qualità di vita per un lungo periodo di tempo.

PAROLE CHIAVE: congiuntivodacriocistorinostomia, ostruzione del dotto nasolacrimale, epifora, questionario sintomi, qualità di vita
Received: May 25, 2020

Accepted: January 10, 2021

Correspondence

Andrea Iandelli

IRCCS Ospedale Policlinico San Martino largo Rosanna Benzi 10, 16132 Genoa, Italy

E-mail: iandelliandrea@gmail.com

Funding

None.

Conflict of interest

The Authors declare no conflict of interest.

How to cite this article: Iandelli A, Carobbio ALC, Migliardi R, et al. Application of a symptoms score questionnaire after conjunctivodacryocystorhinostomy: outcomes. Acta Otorhinolaryngol Ital 2021;41:248-254. https:// doi.org/10.14639/0392-100X-N0881

(C) Società Italiana di Otorinolaringoiatria e Chirurgia Cervico-Facciale

\section{(c) (1) $(2)$}

This is an open access article distributed in accordance with the CC-BY-NC-ND (Creative Commons Attribution-NonCommercial-NoDerivatives 4.0 International) license. The article can be used by giving appropriate credit and mentioning the license, but only for non-commercial purposes and only in the original version. For further information: https:// creativecommons.org/licenses/by-nc-nd/4.0/deed.en 


\section{Introduction}

Nasolacrimal duct obstruction (NLDO) surgery is a shared field between ophthalmologists and otorhinolaryngologists. The development of endoscopic surgery has encouraged rhinological specialists to extend their skills in the management of this pathology.

Conjunctivodacryocystorhinostomy (CDCR) was first described by Von Hoffman in 1904, and later by Kraupa and Goar ${ }^{1}$. CDCR using the insertion of a Pyrex bypass tube, the Jones tube (JT), was first described by Lester Jones in $1962^{2}$ and revolutionised the management of proximal obstruction of the lacrimal drainage system. Nowadays, it represents the gold standard for complete or severe canalicular obstruction and is performed as an additional procedure for failed canalicular surgery, unsuccessful dacryocystorhinostomy (DCR), and refractory lacrimal pump failure ${ }^{2}$.

Endoscopically-assisted placement of the JT gives the surgeon a chance to assess the proper position of the device and, later, tailor its length and angle to avoid painful mucosal contact or decubitus. Considering the presence of a permanent foreign body in the lacrimal canaliculum, it is mandatory to investigate patient discomfort and the ability of the JT to resolve symptoms related to the underlying pathology; while the majority of the published articles on JT conjunctivodacryocystorhinostomy (JT-CDCR) outcomes have focused on the primary surgery and initial success rate $^{3}$, few studies have reported results exceeding one year postoperative and have not considered patient satisfaction and improvement of quality of life $(\mathrm{QoL})^{4}$; therefore, the purpose of this study was to evaluate results after a medium/long period of time and patient satisfaction through relief of symptoms and improved QoL using the Naso Lacrimal Duct Obstruction symptom-score (NLDO-SS).

\section{Materials and methods}

Study design

A multicentric, retrospective and non-comparative study was performed. Patients who underwent endoscopic-guided JT-CDCR from January 2006 to January 2019 in the Otorhinolaryngological Department of San Martino Hospital, Genoa and the Ophthalmology Department of Koelliker Hospital, Turin, were enrolled. In order to avoid any procedural or surgeon bias, all patients enrolled underwent the same surgical technique, step-by-step, as long as each procedure was both anatomically and surgically successful. Each eye and nasal fossa was considered separately.

\section{Preoperative assessment}

Patients were subjected to accurate evaluation to rule out any other common causes of epiphora such as dry eye re- flexed tearing. The preoperative examination included lacrimal irrigation, probing of canaliculi, general ophthalmic evaluation and nasal cavity examination by office-based endoscopy. All patients underwent CT evaluation to assess nasal anatomical variations and to customise the surgical strategy.

\section{Surgical technique}

Endoscopic-assisted CDCR was performed under general or local anaesthesia based on comorbidities and age. An endoscopic minimal-invasive bypass tube was used without dacryocystorhinostomy (DCR) in all patients. A 14-gauge intravenous catheter was introduced through the caruncle with a $45^{\circ}$ downward direction to the nasal cavity. The penetration of the lateral wall of the nasal mucosa, anterior to the middle turbinate, was confirmed by trans-nasal endoscopic control. A graduated Bowman's probe was then passed through the caruncle into the tract using increased diameter probes to enlarge the fistula. The probe graduation reflects the length of Jones tube required. The authors used a $2 \mathrm{~mm}$ Pyrex tube with a flange of $4 \mathrm{~mm}$, inserted through the caruncola. Endoscopic transnasal control was performed to verify the correct position of the tube. At the end of the procedure, the tube was fixed with a suture to the inferior eyelid. A saline solution irrigation verified that the tube was not obstructed. No nasal packing was required for the procedures.

\section{Follow-up}

All patients underwent an endoscopic nasal toilette and debridement 15 and 30 days after the surgery. Patients were followed-up with transnasal endoscopic evaluation and JT effectiveness assessment with saline solution irrigation 6 months post-op and, subsequently, once per year.

\section{NLDO-SS questionnaire}

All patients eligible for the study were contacted by telephone to administer the NLDO-SS questionnaire. The answers were collected by a third party, unrelated to the team that performed the surgery. Patients were assured that their answers would be kept strictly confidential and anonymous and signed consent for the use of collected data. Patients were guided through the questionnaire by the interviewer. The NLDO-SS questionnaire ${ }^{5}$ consists of five items focusing on the common ocular symptoms of NLDO: tearing, discharge in the eye, swelling around the eye, pain around the eye, change in visual acuity; along with two items describing the conditions in the nasal cavity: nose blockage, nasal cavity discharge (Tab. I). In the NLDO-SS, symptoms are graded using an 11-point numeric rating scale (NRS; $0=$ no symptoms, $10=$ worst imaginable symptoms). The 
Table I. NLDO-SS results.

\begin{tabular}{lccccccccccc} 
Case & Tearing & $\begin{array}{c}\text { Purulent } \\
\text { discharge }\end{array}$ & Swelling & Pain & $\begin{array}{c}\text { Loss of } \\
\text { vision }\end{array}$ & $\begin{array}{c}\text { Total ocular } \\
\text { symptoms }\end{array}$ & $\begin{array}{c}\text { Nasal } \\
\text { obstruction }\end{array}$ & $\begin{array}{c}\text { Nasal } \\
\text { discharge }\end{array}$ & $\begin{array}{c}\text { Total nasal } \\
\text { symptoms }\end{array}$ & $\begin{array}{c}\text { Total } \\
\text { Score }\end{array}$ & $\begin{array}{c}\text { FU } \\
\text { time }\end{array}$ \\
\hline 1 & 2 & 0 & 0 & 3 & 0 & 5 & 0 & 0 & 0 & 5 & 49 \\
2 & 1 & 0 & 0 & 0 & 0 & 1 & 0 & 0 & 0 & 1 & 17 \\
3 & 0 & 1 & 0 & 0 & 0 & 1 & 1 & 1 & 2 & 3 & 29 \\
4 & 3 & 2 & 0 & 1 & 0 & 6 & 2 & 1 & 3 & 9 & 29 \\
5 & 3 & 2 & 2 & 0 & 2 & 9 & 1 & 2 & 3 & 12 & 14 \\
6 & 3 & 3 & 0 & 0 & 1 & 7 & 0 & 0 & 0 & 7 & 21 \\
7 & 3 & 0 & 0 & 1 & 1 & 5 & 0 & 0 & 0 & 5 & 21 \\
8 & 3 & 2 & 0 & 0 & 0 & 5 & 0 & 0 & 0 & 5 & 61 \\
9 & 5 & 2 & 5 & 3 & 5 & 20 & 0 & 1 & 1 & 21 & 58 \\
10 & 6 & 2 & 4 & 3 & 5 & 20 & 0 & 1 & 1 & 21 & 58 \\
11 & 2 & 0 & 0 & 0 & 0 & 2 & 0 & 3 & 3 & 5 & 53 \\
12 & 0 & 0 & 0 & 0 & 0 & 0 & 1 & 2 & 3 & 3 & 47 \\
13 & 1 & 0 & 0 & 0 & 0 & 1 & 0 & 0 & 0 & 1 & 46 \\
14 & 5 & 3 & 0 & 2 & 3 & 13 & 0 & 0 & 0 & 13 & 42 \\
15 & 3 & 4 & 2 & 0 & 0 & 9 & 0 & 0 & 0 & 9 & 36 \\
16 & 3 & 3 & 2 & 0 & 0 & 8 & 0 & 0 & 0 & 8 & 36 \\
17 & 1 & 0 & 0 & 0 & 0 & 1 & 0 & 0 & 0 & 1 & 24 \\
18 & 1 & 0 & 0 & 0 & 0 & 1 & 0 & 0 & 0 & 1 & 24 \\
19 & 1 & 0 & 0 & 0 & 0 & 1 & 0 & 0 & 0 & 1 & 75 \\
20 & 1 & 0 & 0 & 0 & 0 & 1 & 0 & 0 & 0 & 1 & 160 \\
21 & 0 & 3 & 2 & 3 & 1 & 9 & 0 & 0 & 0 & 9 & 24 \\
Min & 0 & 0 & 0 & 0 & 0 & 0 & 0 & 0 & 0 & 1 & 14 \\
Max & 6 & 4 & 5 & 3 & 5 & 2 & 2 & 3 & 3 & 21 & 160 \\
Mean & 2.2 & 1.3 & 0.8 & 0.8 & 0.9 & 6.0 & 0.2 & 0.5 & 0.8 & 6.7 & 50,0 \\
Median & 2 & 1 & 0 & 0 & 0 & 5 & 0 & 0 & 0 & 5 & 36,5 \\
\hline
\end{tabular}

NLDO-SS: Naso Lacrimal Duct Obstruction Symptom Score.

total number of points for NLDO-SS ranges from 0 to 70 points. As reported by Pentilla et al., we consider a cut-off point of $\geq 21 / 70$ for failed procedures and $\leq 10 / 70$ for successful ones. Respecting the $1 / 3$ ratio, each variable was investigated considering cut-off points of $\leq 3 / 10$ for successes and $\geq 4 / 10$ for failures in the ability of the procedure to resolve the specific symptom ${ }^{6}$.

\section{Statistical analysis}

GraphPad Prism (San Diego, CA, USA) was used for statistical analysis. Primary surgery versus revision surgery groups comparison analysis was performed using Fisher's exact test or Mann-Whitney test (MWt), as appropriate. A two-tailed p-value $<0.05$ was considered statistically significant.

\section{Results}

A total of 16 patients were recruited. There were 4 males $(25 \%)$ and 12 females $(75 \%)$. The procedure was conduct- ed bilaterally in 5 patients (31.2\%) and unilaterally in 11 (68.8\%), and thus a total of 21 eyes underwent CDCR. The mean age at the moment of surgery was 54 years (range 1676 years). The mean duration of follow-up was 50 months (range 14-160 months), with a median of 36.5 months. The demographic data of the cohort is shown in Table II. All JT were active, and no granulation was detected around the tube rim. The most frequent cause that led to surgery was acquired obstruction secondary to infection and inflammation $(10 / 21 ; 47.6 \%)$, followed by idiopathic stenosis $(5 / 21$; $23.8 \%$ ). The majority of patients underwent revision surgery $(15 / 21 ; 71.4 \%)$, while $6 / 21$ cases $(28.6 \%)$ were primary surgery cases.

The NLDO-SS questionnaire results for each patient are listed in Table II. The total score in our series ranged from a minimum of 1 to a maximum of 21 points. The mean value was 6.7 points with a median of 5 points. The success rate for the procedures in our series was $81 \%$ (17/21 procedures) and was defined by a total score $\leq 10$ points; the fail- 
Table II. Patient demographics, history, pathophysiology.

\begin{tabular}{lcc}
\hline Patients & & \\
Eyes & 216 & \\
Sex & M & $12(75 \%)$ \\
& Min & $4(25 \%)$ \\
Age $(y)$ & Max & 16 \\
& Mean & 76 \\
Follow-up $(m)$ & Min & 54 \\
& Max & 14 \\
& Mean & 160 \\
Cause of the & Median & 50 \\
stenosis & Post-infective/inflammatory & 36.5 \\
& Idiopathic stenosis & $10(47.6 \%)$ \\
& Autoimmune conjunctivitis & $2(23.8 \%)$ \\
Type of surgery & Other causes & $4(19.5 \%)$ \\
& Primary & $15(71.4 \%)$ \\
Laterality & Revision & $6(28.6 \%)$ \\
& Monolateral & $11(68.8 \%)$ \\
& Bilateral & $5(31.2 \%)$ \\
\hline
\end{tabular}

ure rate was $9.5 \%$ (2/21 procedures) and corresponded to a total score of $\geq 21$ points; an intermediate value between 10 and 21 points was registered in $9.5 \%$ of cases $(2 / 21$ procedures). The mean value for ocular symptoms was 6.7 points (range $0-20$ ), with the maximum single symptom score reported for tearing (6 points), followed by swelling and loss of vision (5 points), purulent discharge (4 points) and pain (3 points). The mean value for nasal symptoms was 0.3 points (range $0-3$ ), with the maximum single symptom score reported for nasal discharge (3 points), followed by nasal obstruction ( 1 point). The success rate for single parameters, defined by a score of $\leq 3$, was globally $95.9 \%$ (141/147), 94.3\% (99/105) and 100\% (42/42) for ocular and nasal symptoms, respectively; on the other hand, the failure rate for single parameters, defined by a score of $\geq 4$, was globally $0.4 \%(6 / 147)$, and $0.6 \%$ (6/105) for ocular symptoms and $0 \%(0 / 42)$ for nasal symptoms.

Fisher's exact test did not show any significant difference between the "primary surgery" versus "revision surgery" groups in terms of gender distribution $(p=0.517)$, laterality of the procedure $(p=0.546)$, or success rate $(p=0.053)$. The different distribution of the causes of epiphora was investigated by comparing the two main causes found in our population with the totality of all other possible causes: "postinfective/inflammatory" versus "other causes" $(p=0.149)$ and "idiopathic" versus "other causes" $(p=0.011)$. The scores obtained in the NLDO-SS questionnaire for each symptom were compared in the two groups with the MWt: a significant difference between primary and revision surgery was found for "tearing" score $(\mathrm{p}=0.040)$ and "loss of vision" score $(\mathrm{p}=0.002)$. No difference was found for other ocular symptoms or nasal symptoms. Table III reports the results of statistical analysis.

\section{Discussion}

Canalicular block is a challenge in treatment lacrimal pathway disease. CDCR with the insertion of a Pyrex bypass tube was first described by Lester Jones in $19622^{2}$ and remains the gold standard in surgical treatment of proximal obstruction of the lacrimal drainage system. Since its introduction, the surgical technique has remained unchanged and only a few modifications have been described regarding the shape and angulation of the JT. Furthermore, different fixation techniques have been proposed ${ }^{7,8}$. The success rate of JT-CDCR varies from $57 \%$ to $98 \%$ in different studies ${ }^{4,9}$ and there is great heterogeneity among outcomes evaluated to define the effectiveness of the procedure ${ }^{3}$. In our series, there were significantly more females subjected to CDCR (75\%) with a mean age, similar to other studies, of 53 years ${ }^{10,11}$. The demographic characteristics of our cohort were consistent with the current literature ${ }^{12}$. Acquired NLDO is most commonly encountered in women in their 50 's or older, which seems to be related to the narrowness of the bony nasolacrimal canal and the acute angle between the bony canal and the nasal floor possibly predisposing women to chronic inflammation of the nasolacrimal drainage system ${ }^{13}$. Moreover, postmenopausal hormonal changes may account for this difference between genders ${ }^{14}$. Post-infective/inflammatory sequelae were found to be the most prevalent cause $(47.6 \%)$ in determining the need for JT-CDCR. Chronic inflammation and infections such as blepharitis and recurrent conjunctivitis determine a gradual thickening of the nasolacrimal duct mucosa ${ }^{11}$; furthermore, it is assumed that these conditions are a precursor to external punctal stenosis (EPS) based on inflammatory and cicatricial changes. Chronic disease can result in inflammatory membrane formation, conjunctival epithelial overgrowth and keratinisation of the walls of the punctum ${ }^{15}$. These conditions, therefore, may lead to severe or complete obstruction of EPS with the necessity of JT insertion to restore the patency of lacrimal drainage; an increased risk of outpatient procedure failure (e.g., punctoplasty and balloon dilation) has been reported ${ }^{16}$. Indeed, the majority of procedures in our case series were represented by secondary treatments after failure of outpatient surgery, compared to upfront CDCR (71.4\% vs 28.6\%), confirming the poor trend in response to less invasive treatment. The second most represented cause of NLDO was idiopathic nasolac- 
Table III. Comparison between primary and revision surgery groups and statistical significance.

\begin{tabular}{|c|c|c|c|c|}
\hline Parameter & & Primary & Revision & $\mathrm{p}$-value \\
\hline Gender & Male & $0 / 4(0 \%)$ & $4 / 12(25 \%)$ & $0.517^{\dagger}$ \\
\hline Laterality & Monolateral & $2 / 4(50 \%)$ & $9 / 12(75 \%)$ & $0.546^{\dagger}$ \\
\hline Success & Yes & $3 / 6(50 \%)$ & $14 / 1(93 \%)$ & $0.053^{\dagger}$ \\
\hline \multirow[t]{2}{*}{ Cause } & $\begin{array}{l}\text { Post-infective/ } \\
\text { inflammatory VS others }\end{array}$ & $1 / 6(17 \%)$ & $9 / 15(60 \%)$ & $0.149^{\dagger}$ \\
\hline & Idiopathic VS others & $4 / 6(67 \%)$ & $1 / 15(6.7 \%)$ & $0.011^{\dagger}$ \\
\hline \multirow[t]{7}{*}{ Symptoms (median of scores) } & Tearing & 3 & 2 & $0.040^{\ddagger}$ \\
\hline & Purulent discharge & 2 & 1 & $0.676^{\ddagger}$ \\
\hline & Swelling & 0 & 0 & $0.157^{\ddagger}$ \\
\hline & Pain & 0 & 0 & $0.378^{\ddagger}$ \\
\hline & Loss of vision & 1 & 0 & $0.002^{\ddagger}$ \\
\hline & Nasal obstruction & 0 & 0 & $0.886^{\ddagger}$ \\
\hline & Nasal discharge & 1 & 0 & $0.549 \neq$ \\
\hline
\end{tabular}

${ }^{+}=$calculated with the Fisher's exact test; ${ }^{\neq}=$calculated with the Mann-Whitney test

rimal duct obstruction (INDO), defined as an obstruction in which no cause can be established despite careful history and detailed clinical examination, with a percentage of $23.8 \%$. This data is in line with the present literature ${ }^{14}$. Involutional changes such as aging and tissue atrophy can cause the dense fibrous structure to become less resilient and the surrounding orbicularis fibres to become atonic, resulting in stenosis ${ }^{17}$. This subgroup underwent primary CDCR $(p=0.011)$ significantly more often, most likely due to a lack of evidence of concurrent disease on which to intervene to resolve the underlying cause. In a recent systematic review published by Eisenbach et al. ${ }^{12}$ on 54 articles and 2372 patients, the authors reported a similar distribution among the different aetiologies, although our group did not include any case of post-traumatic or cancer related stenosis. In our retrospective study, we decided to employ NLDO-SS to assess patient satisfaction after an anatomically and surgically successful CDCR procedure. NLDO-SS was originally conceived by Smirnov et al. ${ }^{5}$ to assess outcomes after treatment naso-lacrimal duct obstructions, and we decided to apply the score to our patients since nasolacrimal duct obstruction and canalicular obstruction share the same plethora of symptoms ${ }^{14}$, and both the anatomical subsites participate as a whole to the lacrimal drainage system.

NLDO-SS is not the only tool available to assess postsurgical QoL: Glasgow Benefit Inventory (GBI) and Lacrimal Symptoms Questionnaire (Lac-Q) are also widely used. Although GBI is a well known and validated measure for otorhinolaryngological intervention ${ }^{18}$, it does not provide information about surgical outcomes, is not diseasespecific and does not include ocular symptoms. Lac-Q ${ }^{19}$, similar to NLDO-SS, takes into account the severity of specific ocular symptoms; the most important difference between these two questionnaires is that Lac-Q includes an additional score for social impact, although it does not take into account nasal symptoms. Different authors in the literature reported an efficient application of Lac-Q in their experience and found the questionnaire to be responsive to changes in clinical outcomes ${ }^{20,21}$. However, since most of the procedures used have a nasal endoscopic phase along with septoplasty, middle turbinoplasty, or a partial uncinectomy where appropriate to widen the space for the distal part of the JT and/or avoid mucosal contact and incorrect angle of the tube itself, we preferred to use the NLDO-SS to investigate nasal symptoms which could be related to the procedure. Moreover, the sample of patients used to validate Lac-Q was composed of 29 patients, compared to 76 patients in NLDO-SS, and thus we retain that the latter to be more reliable instrument.

According to the NLDO-SS, we obtained a success rate of $81 \%(17 / 21)$ regarding the total score; this result is in accordance with the average outcomes reported in other studies, which did not use the aforementioned score ${ }^{4}$, highlighting that the NLDO-SS does not deviate consistently from other evaluation systems present in literature. Among the group of failed procedures, the two operations that did not improve the subjective symptomatology, despite objective surgical success, were performed bilaterally on the same patient. This result reveals that a successful surgical outcome does not necessarily confer improvement in QoL ${ }^{22}$. Satisfaction depends, in addition to a well-performed procedure, to a great extent on the patient's expectations, understanding of the nature and function of the tube, as well as to the ability of the surgeon to explain the procedure in detail and its goals and limitations ${ }^{23}$. 
The significant difference in "tearing" $(\mathrm{p}=0.040)$ and "loss of vision" between patients treated with primary CDCR compared to revision group can be interpreted two-fold: firstly, patients who underwent a revision CDRC usually have a long history of epiphora and have already undergone previous procedures (punctoplasty, balloon dilatation, dacryocystorhinostomy) with multiple follow-ups, manipulations, endoscopic nasal debridement and even corrective procedures; furthermore, if the patient has experienced relapses or persistence of symptoms, it might make them more prone to express a higher grade of satisfaction after relief of symptoms, given their personal clinical history ${ }^{24}$. Secondly, a proportion of patients may have underlying subclinical conditions which caused the persistence of the obstruction and symptoms due to improper target therapy. The success rate of CDCR has been demonstrated to be constant with long term follow-up, similar to other series that were conducted for longer periods, and identified that heightened risk of failure (e.g. extrusion, scarring, or granulation) occurs in the first two years post-operative ${ }^{25}$.

\section{Conclusions}

In our experience, JT-CDCR is a reliable procedure and able to improve symptoms in the majority of patients with a good long-term quality of life. The use of a scoring system to assess patient-reported outcomes and satisfaction allows clinicians to evaluate results, success rates and measure any changes of symptoms during follow-up, given that the patency of the lacrimal pathway alone does not necessarily mean satisfaction for the patient.

A thorough assessment is necessary to identify which patients can properly benefit from JT-CDCR. Further prospective studies analysing a larger cohort of patients and longer follow-up are needed to confirm the validity of NLDO-SS in the assessment of post-surgical symptoms after JT-CDCR and the effectiveness of this procedure.

\section{References}

1 Goar LE. Congenital absence of the lacrimal puncta and canaliculi. Trans Am Ophthalmol Soc 1931;29:9199.

2 Jones LT. The cure of epiphora due to canalicular disorders, trauma and surgical failures on the lacrimal passages. Trans Am Acad Ophthalmol Otolaryngol 1962;66:506-524.

3 Sipkova Z, Vonica O, Olurin O, et al. Assessment of patient reported outcome and quality of life improvement following surgery for epiphora. Eye (Lond) 2017;31:1664-1671. https://doi.org/10.1038/ eye. 2017.120

4 Ali MJ, Honavar SG, Naik M. Endoscopically guided minimally invasive bypass tube intubation without DCR: evaluation of drainage and objective outcomes assessment. Minim Invasive Ther Allied Technol 2013;22:104-109. https://doi.org/10.3109/13645706.2012.708347
5 Smirnov G, Tuomilehto H, Kokki H, et al. Symptom score questionnaire for nasolacrimal duct obstruction in adults - a novel tool to assess the outcome after endoscopic dacryocystorhinostomy. Rhinology 2010;48:446-451. https://doi.org/10.4193/Rhino10.069

6 Pentilla E, Smirnov G, Seppa J, et al. Validation of a symptom-score questionnaire and long therm result of endoscopic dacryocystorhinostomy. Rhinology 2014;52:84-89. https://doi.org/10.4193/Rhin. 2014

$7 \mathrm{Na}$ J, Lee S, Park J, et al. Surgical outcomes of endonasal conjunctivodacryocystorhinostomy according to Jones Tube Location. J Craniofac Surg 2017;28:e500-e503. https://doi.org/10.1097/ SCS.0000000000003801

8 Goel R, Kishura D, Nagpal S, et al. Results of a new "mirror tuck technique" for fixation of lacrimal bypass tube in conjunctivodacryocystorhinostomy. Indian J Ophthalmol 2017;65:282-287. https://doi. org/10.4103/ijo.IJO_741_16

9 Passos W, Schellini SA, Padovani CR. Lester-Jones tube: indications and results. Arq Bras Oftalmol 2004;67:863-866. https://doi. org/10.1590/S0004-27492004000600004

10 Woog JJ. The incidence of symptomatic acquired lacrimal outflow obstruction among residents of Olmsted County, Minnesota, 19762000 (an American Ophthalmological Society thesis). Trans Am Ophthalmol Soc 2007; 105:649-666.

11 Trimarchi M, Vinciguerra A, Resti AG, et al. Multidisciplinary approach to lacrimal system diseases. Acta Otorhinolaryngol Ital 2021;41(Suppl. 1):S102-S107. https://doi. org/10.14639/0392-100X-suppl.1-41-2021-10

12 Eisenbach N, Karni O, Sela E, et al. Conjunctivodacryocystorhinostomy (CDCR) success rates and complications in endoscopic vs nonendoscopic approaches: a systematic review. Int Forum Allergy Rhinol 2021;11:174-194 https://doi.org/10.1002/alr.22668

13 Shigeta KI, Takegoshi H, Kikuchi S. Sex and age differences in the bony nasolacrimal canal: an anatomical study. Arch Ophthalmol 2007;125:1677-1681. https://doi.org/10.1001/archopht.125.12.1677

14 Kashkouli MB, Beigi B, Murthy R, et al. Acquired external punctal stenosis: Etiology and associated findings. Am J Ophthalmol 2003;136:1079-1084. https://doi.org/10.1016/ s0002-9394(03)00664-0

15 Edelstein J, Reiss G. The wedge punctoplasty for treatment of punctal stenosis. Ophthalmic Surg 1992;23:818-821.

16 Offutt WN, Cowen DE. Stenotic puncta: microsurgical punctoplasty. Ophthal Plast Reconstr Surg 1993;9:201-205. https://doi. org/10.1097/00002341-199309000-00006

17 Mills DM, Meyer DR. Acquired nasolacrimal duct obstruction. Otolaryngol Clin North Am 2006;39:979-99,vii. https://doi.org/10.1016/j. otc.2006.07.002

18 Robinson K, Gatehouse S, Browning GG. Measuring patient benefit from otorhinolaryngological surgery and therapy. Ann Otol Rhinol Laryngol 1996;105:415-422. https://doi. org/10.1177/000348949610500601

19 Mistry N, Rockley TJ, Reynolds T, et al. Development and validation of a symptom questionnaire for recording outcomes in adult lacrimal surgery. Rhinology 2011;49:538-545. https://doi.org/10.4193/ Rhino11.042

20 Gupta S, Ali MJ, Ali MH, et al. Assessing the outcomes of miniMonoka stent dilatation for primary punctal stenosis using the lacrimal symptom questionnaire. Indian J Ophthalmol 2018;66:269-271. https://doi.org/10.4103/ijo.IJO_799_17

21 Ali MJ, Iram S, Ali MH, et al. Assessing the outcomes of powered endoscopic dacryocystorhinostomy in adults using the lacrimal symptom (Lac-Q) questionnaire. Ophthal Plast Reconstr Surg 2017;33:6568. https://doi.org/10.1097/IOP.0000000000000660 
22 Ho A, Sachidananda R, Carrie S, et al. Quality of life assessment after non-laser endonasal dacryocystorhinostomy. Clin Otolaryngol 2006;31:399-403. https://doi.org/10.1111/j.1749-4486.2006.01278.x

23 Rosen N, Ashkenazi I, Rosner M. Patient dissatisfaction after functionally successful conjunctivodacryocystorhinostomy with Jones tube. Am J Ophthalmol 1994;117:636-642. https://doi.org/10.1016/ s0002-9394(14)70070-4
24 Joshi R, Deshpande A. Success rate of conventional dacryocystorhinostomy in post-acute dacryocystitis compared to endonasal dacryocystorhinostomy in acute dacryocystitis. J Ophthalmic Vis Res 2017;12:290-295. https://doi.org/10.4103/jovr.jovr_264_15

25 Scawn RL, Verity DH, Rose GE. Can Lester Jones tubes be tolerated for decades? Eye (Lond) 2018;32:142-145. https://doi.org/10.1038/ eye. 2017.168 